\title{
Climatological Trend of Sea Surface Temperature Anomalies in the South Eastern Mediterranean Sea
}

\author{
I.A. Maiyza and M.S. Kamel \\ National Institute of Oceanography \& Fisheries, \\ Kayet-Bey, Alexandria, Egypt \\ Ia_maiyza@hotmial.com_mskamela@yahoo.com
}

\begin{abstract}
The Linear and quadratic regressions have been used to investigate the relationship between SSTA and time (month or year) to get the general SSTA possible trends. Regardless the propaganda concerning increasing or oscillating of climate parameters. The present work depends on analyzing series of observed data (61 years, January 1948 to December 2008) for a limited geographic area (south eastern Mediterranean Sea in front of the Egyptian Mediterranean coast). The linear regression and model results reveal a trend of general decrease of SST with time in the order of about $-0.3^{\circ} \mathrm{C} / 61$ years. The quadratic regression trend of the mean monthly and annual SST has a parabola form. The parabolas show a decrease in SST in the period from 1948 to 1985 then increasing forward. The present work may strengthen the suggestion of oscillating sea surface temperature (SST) with time rather than continuous increasing due to the so called global warming. The cycle of that oscillation must have a period much more than 61 years and may reach to centuries.
\end{abstract}

Keyword: Mediterranean, SSTA, Trend.

\section{Introduction}

The study of sea surface temperature anomaly (SSTA) is fairly essential for solving many meteorological and oceanographic problems (Heburn, 1985). The duration and wide occupation of SSTA gives the reason to study it as one of the main factors affecting climatic system of the earth (Fedrouich, 1985 and Levitus, 1995). Marullo et al. (2007) and Salat \& Pascual (2007) studied the sea surface temperature trend in the 
Mediterranean Sea, from daily to decadal variations. They suggested both increasing and oscillating of the mean sea surface temperature (SST) with time. For the sea, not only studies about hydrological trends but also studies about dense water formation and circulation must take into account the Interannual variability (Millot, 2007).

Maiyza (1984) and Maiyza et al. (1995) studied the long term variation of water temperature in the eastern and western Mediterranean Sea. Time distribution of SSTA values display both positive and negative cycles. The periods of these cycles fluctuated between 8 and 15 years. These cycles are nearly associated with the 11 year cycle of sun-spots activities (Maiyza et al., 2008).

In this paper, the linear and quadratic regressions have been used to investigate the relationship between SSTA and time (month or year) to get the general SSTA possible trends (increasing or decreasing temperature). In the present work the long period trends in series of SSTA (monthly and annual) are used as an indicator of temperature change regardless the present propaganda concerning increasing or oscillating of climate parameters. The work depends on analyzing series of observed data (61 years) for a limited geographic area (South Eastern Mediterranean Sea).

\section{Data and Method of Analysis}

The area under study is the south eastern Mediterranean Sea in front of the Egyptian Mediterranean coast (the southern part of the Levantine Basin). It lies between $3050^{\prime}-33^{\circ} \mathrm{N}$ and $25-34^{\circ} \mathrm{E}$ basin (Fig. 1).

The vertical mean temperature of the upper $10 \mathrm{~m}$ layer is considered as SST to reduce the diurnal variations. The monthly mean sea surface temperature $(\mathrm{T})$ is calculated for each $1^{\mathrm{o}} \times 1^{\mathrm{o}}$ grid (18 grids, Fig. 1) for every individual month in the period from January 1948 to December 2008 using the available historical WDC-A (Washington D C), WDC-B (Moscow) and Egyptian National Oceanographic Data Centre (ENODC) Data files. The mean monthly Sea surface temperature $\left(\mathrm{T}^{* *}\right)$ is obtained from the Climatological Atlas of the Mediterranean Sea (Maiyza et al., 1993). The monthly deviation from the mean $\left(\Delta \mathbf{T}_{\mathbf{m}}\right)$ is computed and considered as monthly SSTA for every grid.

$$
\Delta \mathbf{T}_{\mathrm{m}}=\mathbf{T}-\mathbf{T}^{* *}
$$




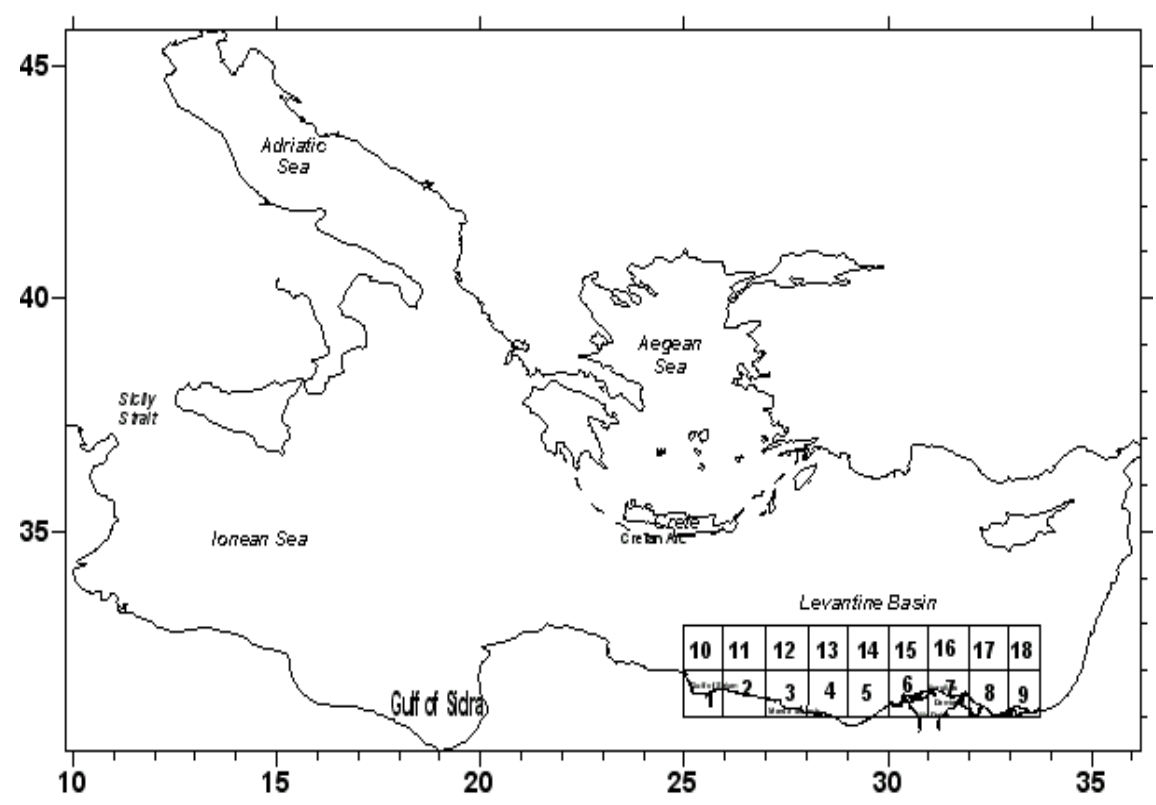

Fig. 1. Area of investigation, the south eastern Mediterranean sea.

The mean monthly SSTA of all grids is considered as the monthly SSTA of the area under study. Then the mean annual SSTA, for every calendar year, $\left(\Delta \mathbf{T}_{\mathbf{a}}\right)$ in the investigated period $(1948-2008)$ are determined.

Linear and quadratic regressions have been used, on the calculated mean monthly SSTA and mean annual SSTA, to investigate and model the relationship between SSTA $\left(\mathrm{Y}^{\circ} \mathrm{C}\right)$ and time $(\mathrm{X}$; month or year) to get the SSTA possible trends through the period of investigation. The four regression equations for the long-term tendency of a SSTA series to rise or fall (upward trend or downward trend) were calculated and presented.

\section{Results and Discussion}

Figure 2(a,b) shows the linear regression and model the relationship between mean monthly and mean annual SSTA respectively with time (month or year) for the period of investigation. The result reveals a trend of general very slight decrease of SSTA, and consequently SST, with time in the order of about $-0.3^{\circ} \mathrm{C} / 61$ years $(1948-2008)$. 


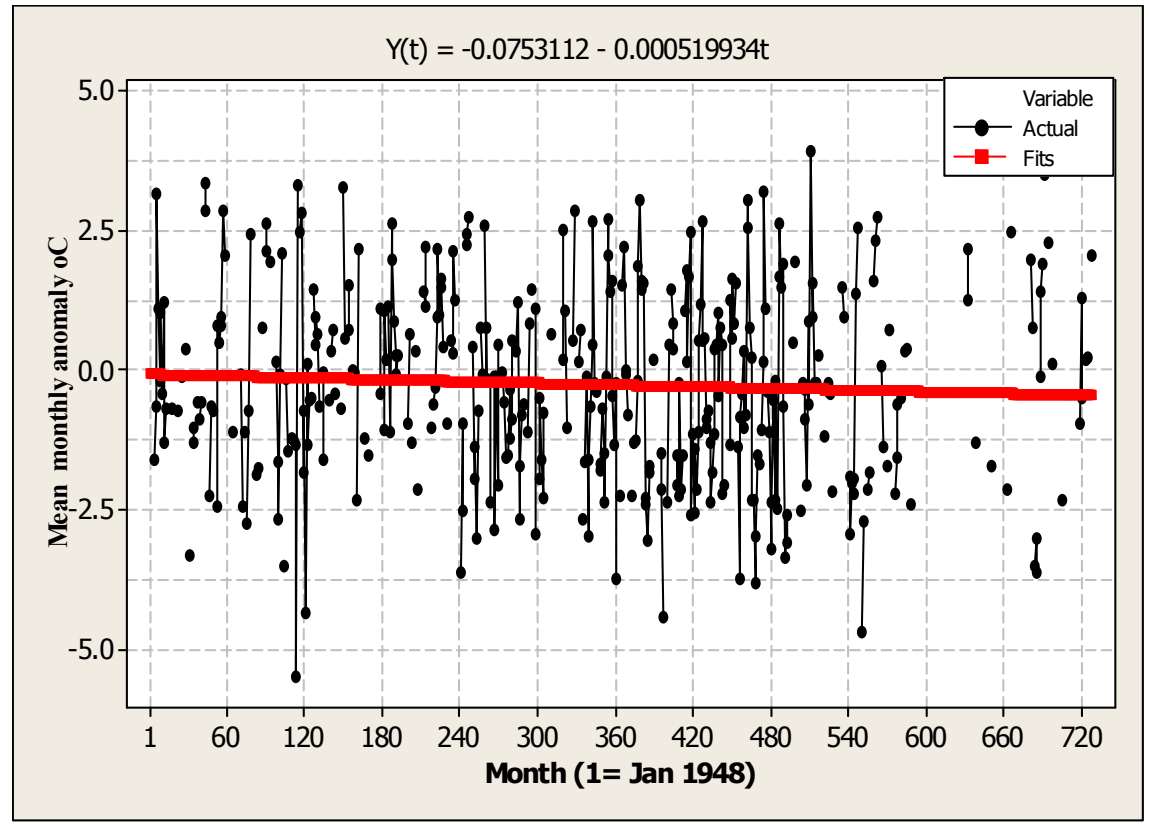

Fig. 2a. Linear trend analysis plot for mean monthly SSTA.

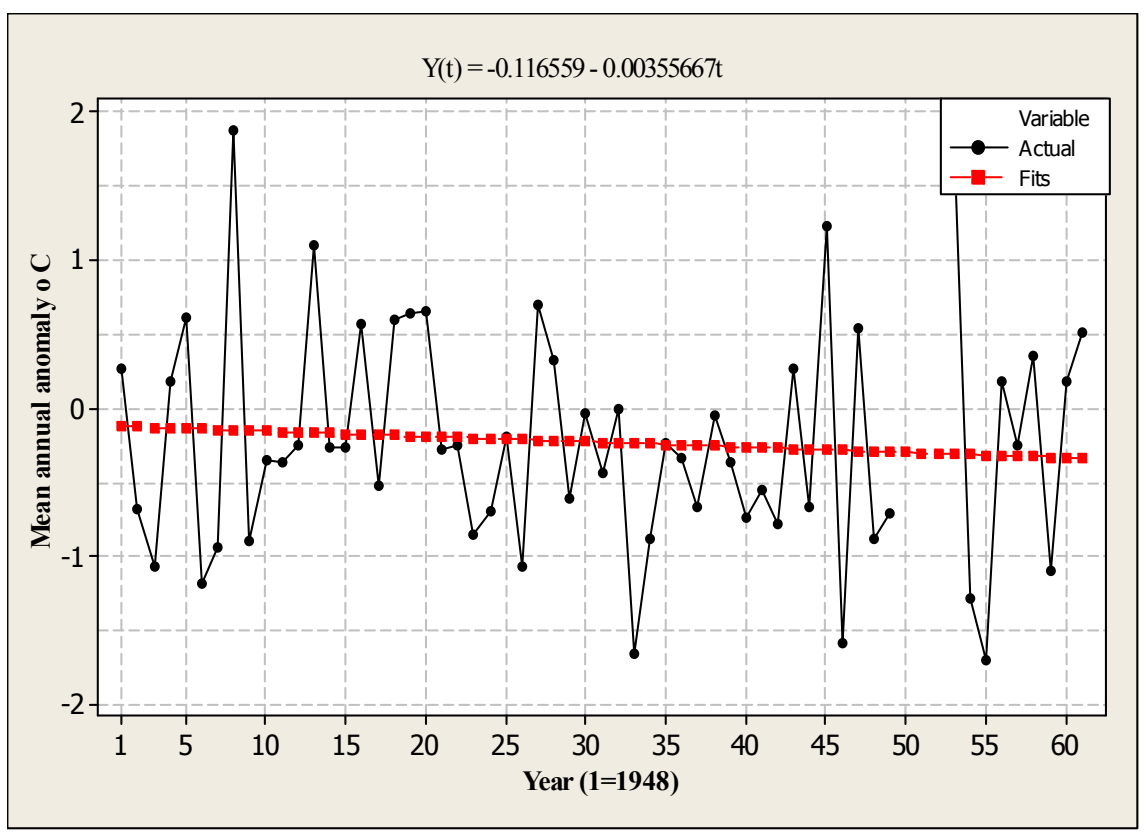

Fig. 2b. Linear trend analysis plot for mean annual SSTA. 
The linear model for the mean monthly SSTA trend has the form:

$$
y(t)=-0.0753112-0.000519934 t
$$

Where: $\mathrm{t}(1$ to 732$)=\mathrm{t}($ Jan, 1948 to Dec, 2008).

While the linear model for the mean annual SSTA trend has the form:

$$
y(t)=-0.116559-0.00355667 t
$$

Where: $\mathrm{t}(1$ to 61$)=\mathrm{t}(1948$ to 2008$)$.

These two linear modes show a trend of continuous decrease of SSTA with time and consequently SST when applying the reverse of Equation (1) in the form:

$$
\mathbf{T}=\Delta \mathbf{T}_{\mathbf{m}}+\mathbf{T}^{* *}
$$

Figure 3(a,b) shows the quadratic regression and model the relationship between $\Delta \mathrm{Tm}$ and $\Delta \mathrm{Ta}$ respectively with time (month or year) for the period of investigation.

The quadratic model for the mean monthly SSTA trend has the form:

$$
y=0143100-0.00234735 t+2.711817 E-06 t^{2}
$$

While the quadratic model for the mean annual SSTA trend has the form:

$$
y=0.00962704-0.0156062 t+0.000195383 t^{2}
$$

The quadratic regression trend of the mean monthly and annual SSTA has a parabola form. The parabolas show a decrease in SSTA, and consequently SST, in the period 1948 to 1985 then increasing forward.

\section{Summary and Conclusions}

The linear and quadratic regressions have been used to investigate the relationship between SSTA and time (month or year) to get the general SSTA possible trends.

Regardless the propaganda concerning increasing or oscillating of climate parameters. The present work depends on analyzing series of observed data (61 years, January 1948 to December 2008) for a limited geographic area (south eastern Mediterranean Sea in front of the Egyptian Mediterranean coast). 


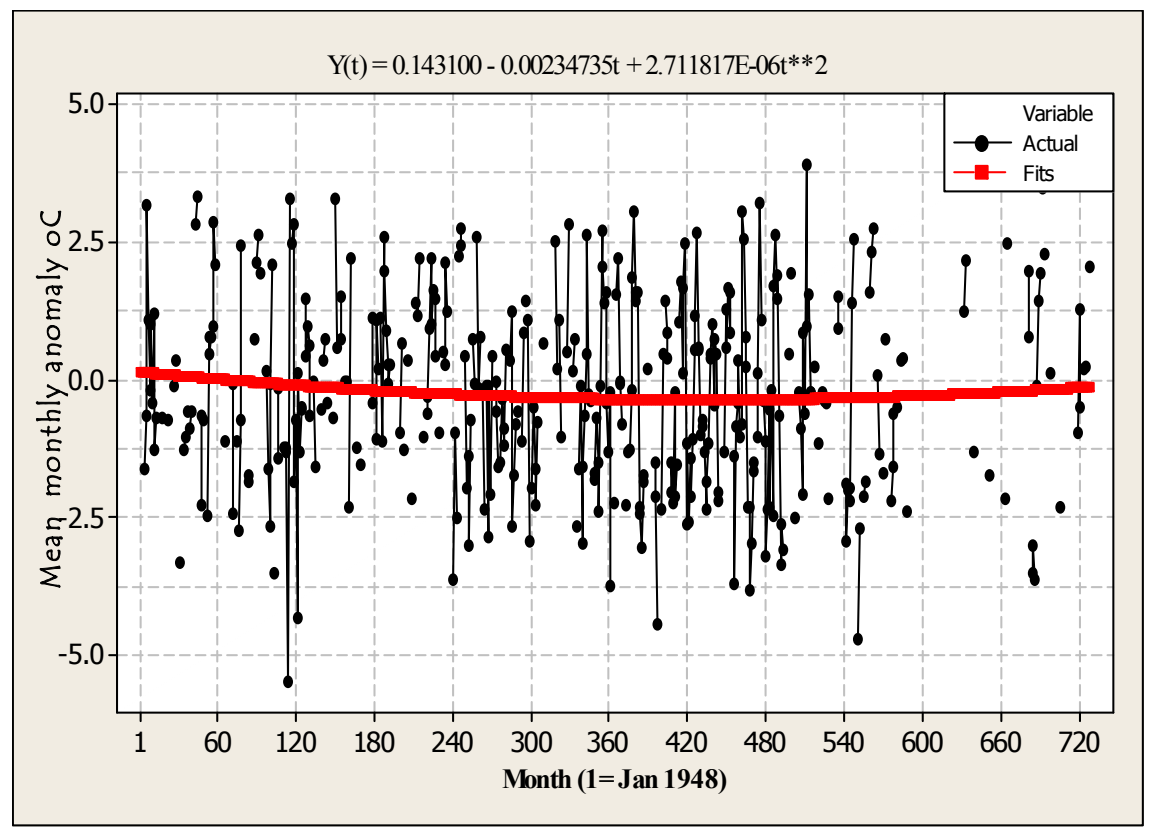

Fig. 3a. Quadratic trend analysis plot for mean monthly SSTA.

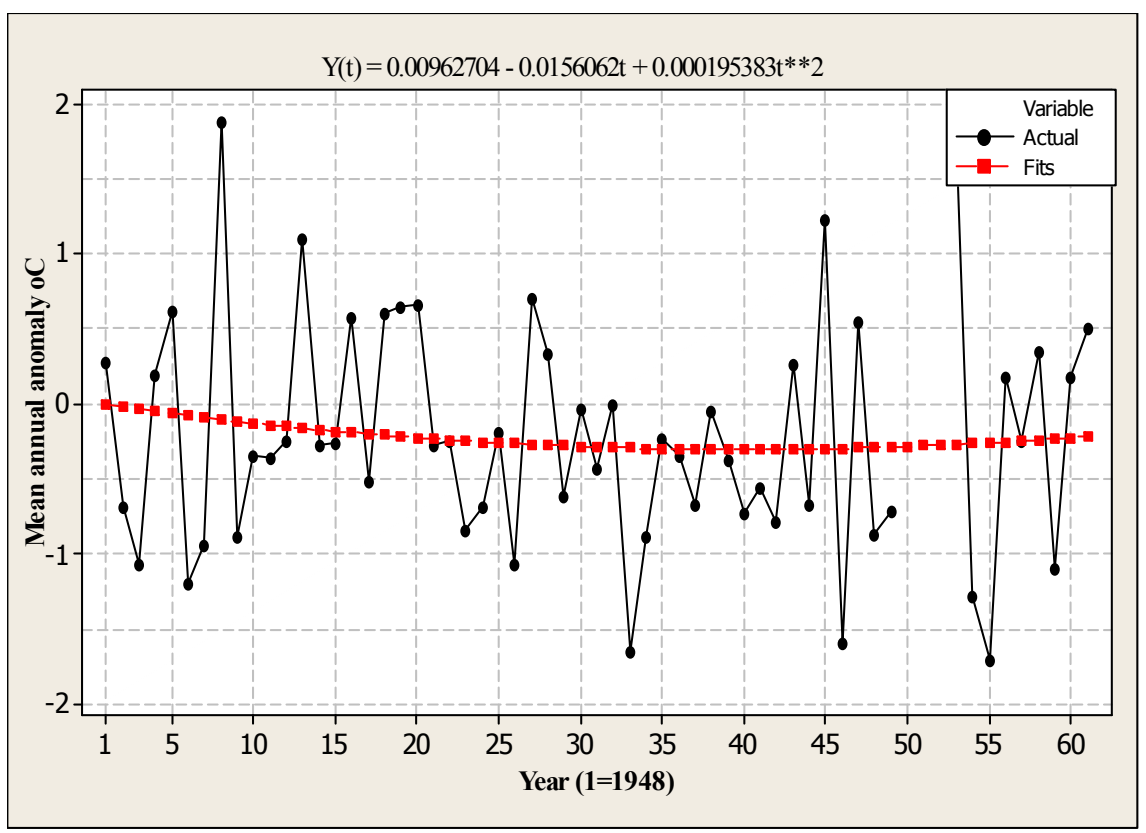

Fig. 3b. Quadratic trend analysis plot for mean annual SSTA. 
The linear regression and model results reveal a trend of general decrease of SST, with time in the order of about $-0.3^{\circ} \mathrm{C} / 61$ years. The quadratic regression trend of the mean monthly and annual SST has a parabola form. The parabolas show a decrease in SST in the period from 1948 to 1985 then increasing forward.

The present work may strengthen the suggestion of oscillating sea surface temperature (SST) with time rather than continuous increasing due to the so called global warming. The cycle of that oscillation must have a period much more than 61 years and may reach to centuries.

\section{References}

Fedrouich, L.A. (1985) Regular formation of large scale temperature anomalies of the surface layer in the northern Pacific Ocean, Ph.D. Thesis, Moscow Univ., 24 p.

Heburn, G.W. (1985) Effect of wind versus hydraulic forcing on the dynamics of the western Mediterranean Sea, Rapp. Comm. Int. Mer Medit., 29: 3.

Levitus, S. (1995) Interannual to decadal scale variability of the world Ocean, IAPSO XXI General Assembly, Honolulu, Hawaii, USA, August 5-12, 1995).

Maiyza, I.A., Mohamed, E.E. and Badawi, H.K. (1993) Climatological Atlas of the Mediterranean Sea, Bull. Nat. Inst. Ocn. \& Fish., A.R.E., 19: 3 Vll.

Maiyza, I.A. (1984) Long term variation of water temperature in the eastern part of the Mediterranean Sea, Ph. D. Thesis, Moscow Univ., 240p (in Russian).

Maiyza, I.A., Said, M.A. and Kamel, M.S. (2008) Sea Surface Temperature Anomalies in the South Eastern Mediterranean Sea. (Submitted).

Maiyza, I.A., Mohamed, E.E., Saad, N.N. and Sharaf El-Din, S.H. (1995) Sea surface temperature anomalies in the western Mediterranean, IAPSO XXI General Assembly, Honolulu, Hawaii, USA, August, 5-12.

Marullo, S., Santoleri, R., Guarracino, M., Buongiorno Nardelli, B. and Artale, V. (2007) Sea surface temperature trend of the last 125 years in the Mediterranean Sea: from daily to decadal variations, Rapp. Comm. Int. Mer Medit., 38: 169.

Millot, C. (2007) Interannual salinification of the Mediterranean inflow, Geophysical Research Letters, Vol. 34, LXXXXX, doi:, 10: 1029 GL0 3:1179.

Salat, J. and Pascual, J. (2007) Climatological trend from 32 years of observations at L'Estartit station, near the Catalan coast (NW Mediterranean), Rapp. Comm. Int. Mer Medit., 38: 196. 


\section{اتجاه حيود درجة حر ارة المياه السطحية \\ في جنوب شرق البحر المتوسط}

\section{إبر اهيم أمين معيزة، و محمد سلامه كامل}

المعهد القومي لعلوم البحار و المصايد، الإسكندرية - مصر

المستخلص. استخدم التنرج الخطي و التزبيعي الإحصائي لدراسة العلاقة بين المتوسطات الثهرية والسنوية لحيود درجات حرارة المياه السطحية مع الزمن للحصول على أتجاه الانحدار العام لهذه

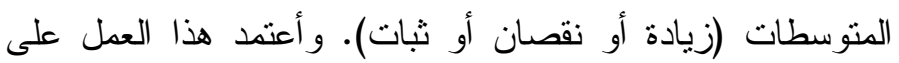

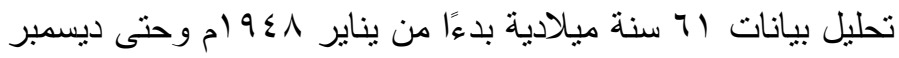

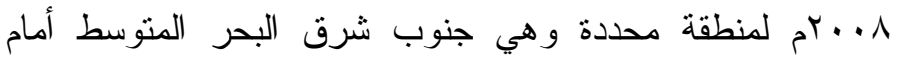

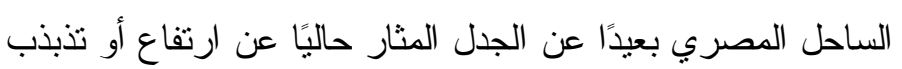

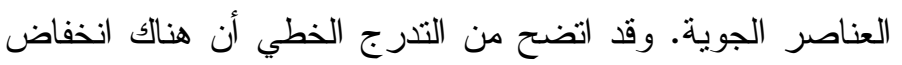

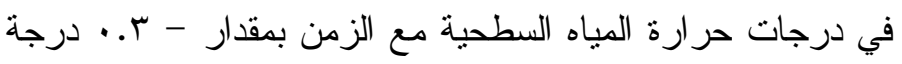

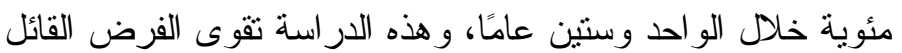

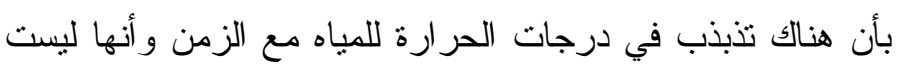

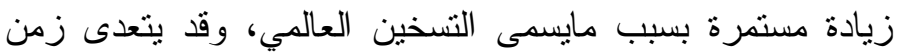
التذبذب الو احد وستين عامًا بكثير وربما يصل إلى قرون. 